\title{
Análisis estructural y morfotectónico al norte de Valledupar-Cesar, Colombia: contribución a los estudios de peligrosidad sísmica de la Falla Río Seco
}

\author{
Structural and morphotectonic analysis to the north of Valledupar-Cesar, \\ Colombia: contribution to the studies of seismic danger of the Rio Seco Fault
}

\author{
Frank David Lascarro Navarro ${ }^{1}$ \\ Milton David Lozada Molina ${ }^{1}$ \\ Dino Carmelo Manco Jaraba ${ }^{2 *}$ \\ Elías Ernesto Rojas Martínez ${ }^{3}$ \\ Recibido 13 de septiembre de 2018, Aceptado 31 de enero de 2019 \\ Received: September 13, 2018 Accepted: January 31, 2019
}

\begin{abstract}
RESUMEN
La Falla Río Seco es una estructura de tipo dextral que se extiende en dirección E-W, se encuentra ubicada en las estribaciones de la Sierra Nevada de Santa Marta y se prolonga por $70 \mathrm{~km}$ en el área de las planchas geológicas 26 y 27 realizadas por el Servicio Geológico Colombiano. Este trabajo tiene como objetivo, contribuir a los estudios de peligrosidad sísmica de la región, mediante la realización de un análisis estructural y morfotectónico de la Falla Río Seco. Con base a información obtenida del Servicio Geológico Colombiano, se realizó inicialmente una revisión de la sismicidad histórica en esta zona del departamento y un análisis por imágenes satelitales Sentinel 2A, que permitió examinar los rasgos estructurales y unidades geomorfológicas del sector. Seguidamente se llevó a cabo una campaña de campo, cartografiando un tramo de la falla en los sectores de las poblaciones de Río Seco - Murillo, analizando indicios de deformación activa, fallas asociadas y rasgos morfotectónicos que previamente fueron identificadas mediante la interpretación de imágenes satelitales de la zona. Se aplicaron técnicas paleo sísmicas como la realización de trincheras sobre el abanico aluvial, donde se encontraron pequeños cambios en la dirección de los clastos en las paredes de la excavación, y deformaciones que no superan los ocho centímetros sobre el perfil de suelos, lo que indica actividad neotectónica pasiva. Continuamente se procedió a la toma de 367 datos estructurales a lo largo de este tramo del trazo de la falla para conocer la dirección de los esfuerzos, empleando el software Faulking y FaultKinWin, determinándose una cinemática preferencial dextral asociadas al Sistema de Fallas NE-SW.
\end{abstract}

Palabras clave: Análisis estructural, esfuerzos, Falla Río Seco, morfotectónica, neotectónica, paleosismicidad.

\section{ABSTRACT}

The Río Seco fault is a type of dextral structure that extends in the EW direction, located between the foothills of the Sierra Nevada de Santa Marta and extends $700 \mathrm{~km}$ in the area of geological maps 26 and 27 made by the Colombian Geological Service. This investigation aims to contribute to seismic Hazard studies of the region, by performing a structural and morphometric analysis of the Río Seco Fault. Based on information obtained from Colombian Geological Service, a review of the historical

\footnotetext{
1 Fundación Universitaria del Área Andina. Valledupar, Colombia. E-mail: flascarro@estudiantes.areandina.edu.co; milozada@estudiantes.areandina.edu.co

2 Universidad de La Guajira. Dirección de Investigación, Riohacha, Colombia. E-mail: dinomancojaraba@ gmail.com

3 Fundación Universitaria del Área Andina. Valledupar, Colombia. Grupo GIINGEO. E-mail: eliaser@ hotmail.com

* Autor de correspondencia: dinomancojaraba@ gmail.com
} 
seismicity in this area of the department and an analysis by satellite images Sentinel $2 A$ were initially carried out, which allowed examining the structural features and geomorphological units of the sector. A field campaign was then carried out, mapping a section of the fault in the sectors of the Rio Seco - Murillo populations analyzing sings of active deformation, previously identified by interpreting satellite images of the area. Paleo-seismic techniques were applied as the realization of trenches on the alluvial fan, where small changes in the direction of the clasts were found in the walls of the excavation, and deformations that did not exceed eight centimeters on the profile of the soils, indicating passive neotectonics activity. It was continuously taken to take 367 structural data along this section of the stroke of the fault to know the direction of the efforts, using the software Faulking and FaultKinWin, determining a preferential kinematics dextran associated with the system NE-SW faults.

Keywords: Efforts, structural analysis, morphotectonic, neotectonics, paleoseismicity, Rio Seco fault.

\section{INTRODUCCIÓN}

Alrededor del mundo se han reportado muchos casos y ejemplos de eventos sísmicos muy conocidos en zonas relativamente estables. En Australia cerca de Marryat Creek, se reportó un sismo de magnitud 5.8, ocurrido el 30 de marzo de 1986 como consecuencia de la reactivación de movimientos en las fallas, [1-2]. Por otra parte, se reportaron sismos en Tennant Creek, Austria con magnitud 6,3 a 6,7 el 22 de enero de 1988, y sismos con magnitud 6,4 el 29 de septiembre de 1993 en Killari, India. Estos antecedentes, similares a eventos sísmicos en la Falla Río Seco justifican la realización de este trabajo, en esta zona de bajo nivel sísmico en el norte de Colombia, donde se han detectado contrastes geodinámicos de desplazamiento horizontal de $5 \mathrm{~mm} /$ año y 3 a $14 \mathrm{~mm} /$ año, a lo largo de la Falla de Oca y del Sistema de Fallas de Santa Marta-Bucaramanga respectivamente [3-5].

A diferencia de la región occidental colombiana localizada en un límite de placas activa por la interacción entre las placas Nazca y Suramericana, el municipio de Valledupar se ubica en una zona relativamente estable según el Servicio Geológico Colombiano (SGC) [6], sin embargo, desde el año 2001 se han reportado sismos asociados a la Falla Río Seco con magnitudes variables en la escala de Richter entre 1,3 a 4,4 y profundidades entre 0 a $940 \mathrm{~km}$ [7]. Esto unido a la capacidad de amplificación sísmica de las unidades geológicas presentes en el área, sobre los que se desarrolla el principal asentamiento humano cercano a la falla (corregimiento Río Seco), influyeron en la necesidad de profundizar en el conocimiento estructural mesoscópico del substrato geológico y morfoestructural del relieve, en la población de Río Seco, norte del municipio de
Valledupar, Cesar, Colombia, con fines de contribución a los estudios de zonificación de riesgo sísmico, mediante la determinación de análisis estructurales y morfotectónicos de la Falla Río Seco. El área de estudio cubre una porción entre dos morfologías tectónicas, el margen oriental de la Sierra Nevada de Santa Marta y la parte centro-occidental de la Cuenca Cesar-Ranchería, cuyo límite está localizado dentro de la Región Estructural IV, constituido por estructuras rumbo-deslizantes dextrales con rumbos NE-SW vergentes al NW [3] (Figura 1).

El análisis estructural y morfotectónico de la Falla Río Seco permite conocer datos específicos sobre su trazo, dirección de esfuerzos preferencial, deformaciones en la rocas y rasgos geomorfológicos, indicios que muestra el comportamiento de la falla y que aportan nuevos conocimientos a los estudios de peligrosidad sísmica de una región.

\section{MARCO GEOLÓGICO}

La zona de trabajo se ubica en el piedemonte oriental de la Sierra Nevada de Santa Marta y la parte centrooccidental de la Cuenca Cesar-Ranchería, en el corregimiento de Río Seco, municipio de Valledupar, Cesar, Colombia. Esta área se caracteriza por presentar una variedad de rocas metamórficas antiguas del Proterozoico y Devónico, rocas ígneas Triásico - Jurásicas de diferentes ambientes geológicos, y depósitos del Cuaternario. Colmenares, F., et al., (2007) [3], agrupa estas rocas en diferentes unidades, Granulita de Los Mangos (Pem), Formación Corual, Ignimbrita de Los Clavos (Jlc), Riodacita de Los Tábanos (Jt), Terrazas aluviales (Qt), Abanicos y gravas $(\mathrm{Qg})$, formaciones geológicas pertenecientes al área (Figura 2). 
Fuente: Autores.
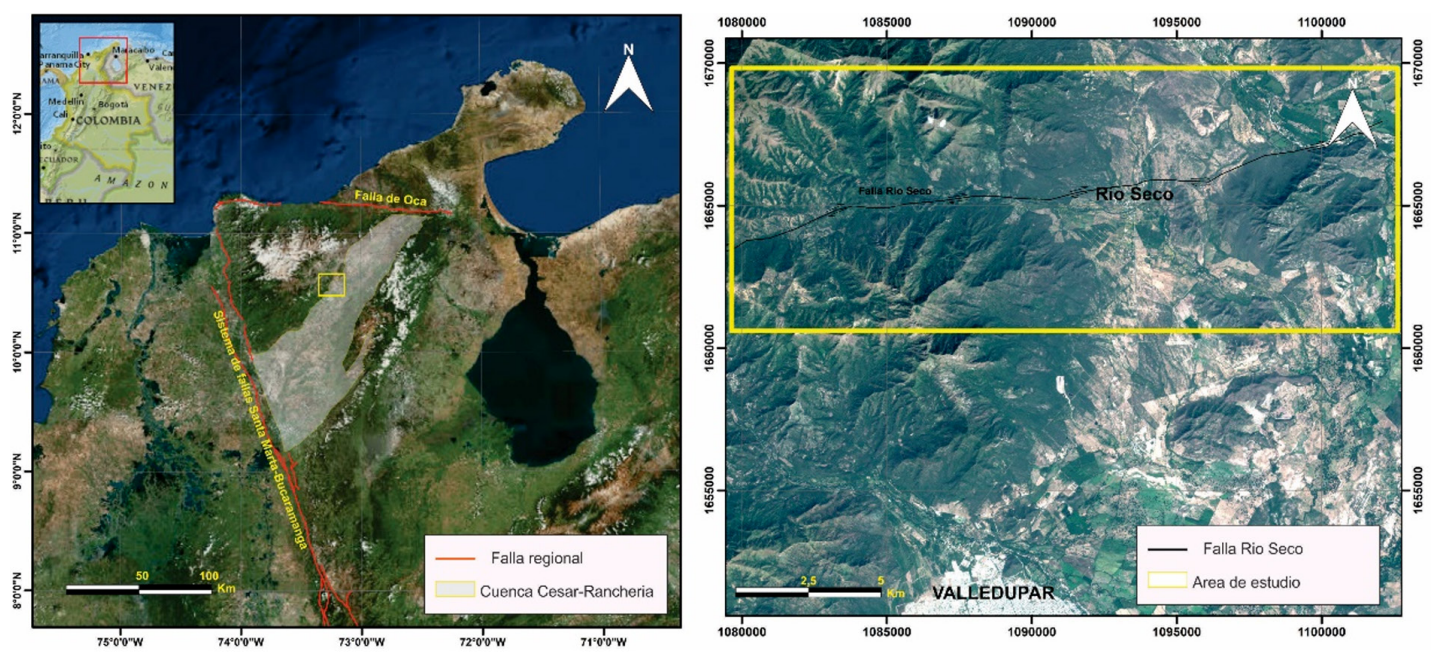

Figura 1. Área de localización. En esta se muestran los principales sistemas de fallas regionales (Falla de Oca y Sistema de Fallas Santa Marta-Bucaramanga) y el trazo de la Falla Río Seco.

Fuente: Colmenares, F., et al., 2007.
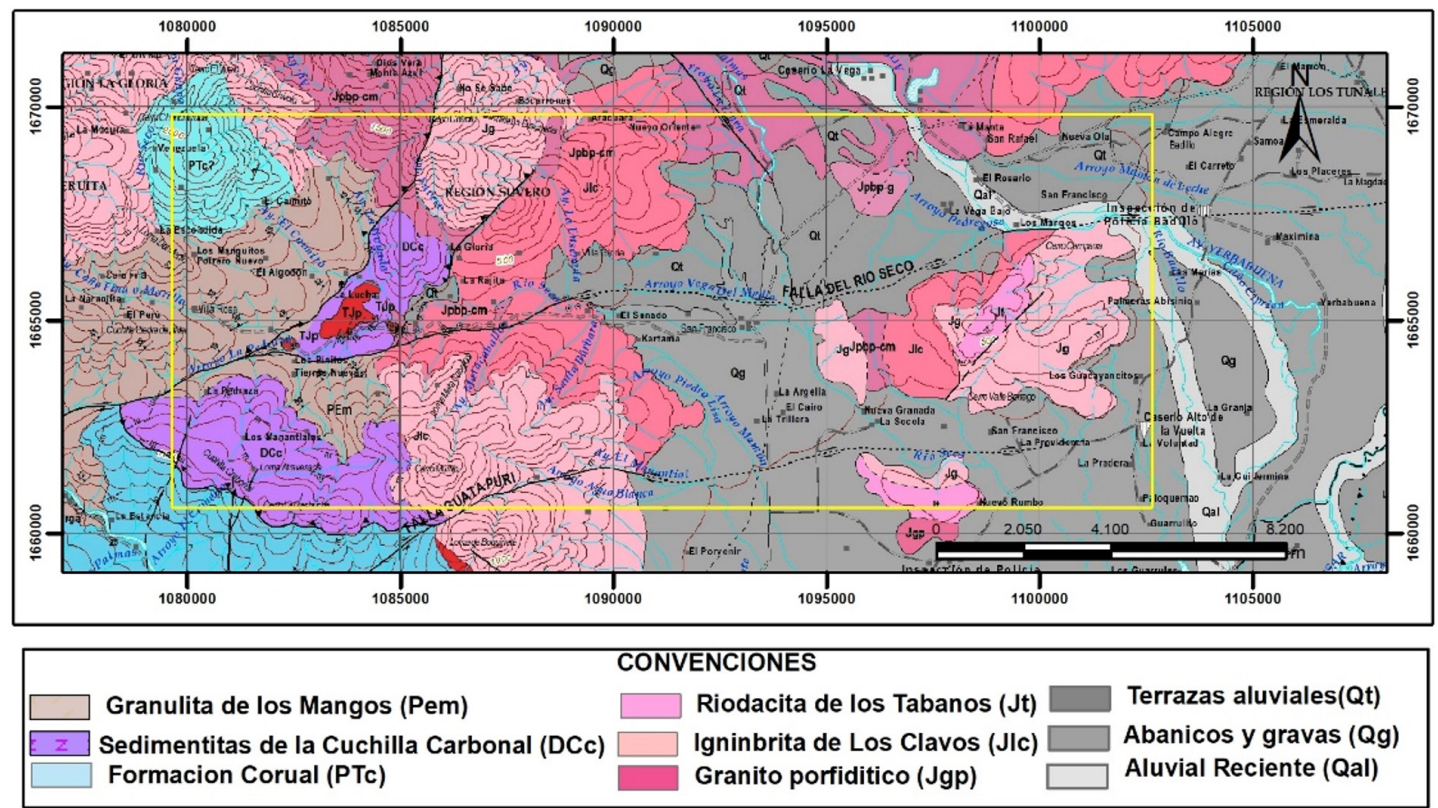

Figura 2. Geología de la plancha 27, donde se identifican las unidades de rocas pertenecientes al área de estudio.

\section{Marco tectónico}

Estructuralmente, el departamento del Cesar se encuentra estandarizado por dos grandes sistemas de fallas principales que están concentrados sobre las estribaciones de la Sierra Nevada de Santa Marta al norte, y hacia es este con la Serranía del Perijá.
Estas fallas están caracterizadas en gran parte por ángulos de inclinación altos, e importantes desplazamientos laterales regionales como la Falla de Oca y Falla Santa Marta-Bucaramanga. Se puede definir la Falla Oca con una estructuralidad lineal de forma simple con una extensión aproximada 
de $10.000 \mathrm{~km}$, con rumbo E-W siendo estudiada a lo largo de los años, como una falla de rumbo dextral con buzamiento desconocido. Esta falla establece el límite entre la Sierra Nevada de Santa Marta y la depresión de la Baja Guajira y entre la primera y el Mar Caribe. El trazo de esta falla es aproximadamente recto y cuenta con ligeras flexiones de muy bajo ángulo [3].

\section{Sistema de Fallas NE-SW}

El sistema de fracturamiento NE-SW controla el drenaje en la zona montañosa del departamento del Cesar y es apreciado en imágenes de satélite, fotografías aéreas y mapas topográficos [8]. Las fallas pertenecientes a este sistema son las Fallas de Curibá, Mamancanaca, Tierra Nueva, Río Seco, Ariguanicito, Las Minas, Maízmorocho, Las pavitas, Diluvio (Figura 3), La Piña, El Golero y varias sin denominación en la parte sur. Dentro de este Sistema NE-SW se encuentran las fallas cubiertas en la parte plana, por depósitos cuaternarios provenientes del Río Cesarito, Río Cesar, San Diego - Cuatro Vientos, Media Luna y Chorro - Pital.

\section{Falla Río Seco}

La Falla Río Seco es una estructura dextro lateral enmarcada dentro del sistema NE-SW [8], se encuentra cortando el trazo de las Fallas Tierra Nueva, Guatapurí y Patillal, las cuales tienen comportamiento dextral en dirección NE-SW (Figura 3). Esta Falla sigue el curso de los ríos los Mangos, Río Seco y San Sebastián. Su tramo más oriental queda sepultado bajo depósitos cuaternarios que se extienden hacia el río Cesar [3].

\section{Sismicidad y movimientos tectónicos recientes}

El Catálogo de Sismos de Colombia para estudios de amenaza sísmica, contiene sismos preinstrumentales e instrumentales, y se elaboró con información tomada del catálogo de terremotos para América del Sur en la parte colombiana, periodo 1566 a 1981 [9].

La evaluación de la amenaza sísmica con fines de reducción de la vulnerabilidad de las estructuras ante la eventualidad de un sismo no puede basarse exclusivamente en el análisis de la sismicidad de una región, ya sea registrada en forma instrumental (sismicidad instrumental) o evaluada a partir del análisis crítico de documentos históricos (sismicidad histórica) [10]. La razón es que algunos de los grandes terremotos son de baja recurrencia y su periodo de retorno es mayor que la tradición escrita de la región y que el registro instrumental. Además, en zonas tectónicamente activas, de gran complejidad estructural, donde la sismicidad está distribuida en una franja de deformación, se dificulta la asociación sismotectónica de dicha actividad con la estructura. Varios autores [11], han demostrado que para algunas fallas los grandes terremotos no se rigen por la ley de GutenbergRichter, que relaciona frecuencia de terremotos y magnitud, la cual sí es generalmente válida para sismos con magnitud inferior a 5,5 grados en la escala de Ritcher [12-13].

Al norte de Valledupar, Cesar, la Falla Río Seco constituye el rasgo morfoestructural y geodinámico más relevante del área. A esta zona de falla se asocian sismos con magnitudes entre 1,3 a 4,4 en la escala de Richter y profundidades entre 0 a $940 \mathrm{~km}$ [6]. Sin embargo, los eventos sísmicos entre los años 2010 y 2017, son destacables los sismos de magnitud 3,9 en la población de Río Seco, con profundidades de $89.9 \mathrm{~km}$ y $88.0 \mathrm{~km}$ en los años, correspondiente a los años 2013 y 2015 respectivamente, lo que indica actividad sísmica en el área (Tabla 1).

En la elaboración de la Figura 4 se emplearon los catálogos de la Red Sismológica Nacional [7], donde se destaca que la sismo estadística reporta 4 eventos de magnitud de 1 a 2, 6 eventos de magnitudes de 2 a 3 , y 2 eventos de magnitud mayores a 3 en la escala de Richter, entre los años 2010 a 2017 (Tabla 1). Esta misma enmarca la distribución de sismos alrededor de la Falla Río Seco y de estructuras asociadas a la misma, mostrándose la zona como un área de baja sismicidad, sin embargo, esto no debe ser un factor tranquilizante, debido a los sismos de gran magnitud como el de Marryat Creek, en Australia con magnitud 5,8 en la escala de Richter, en una zona considerada de baja sismicidad [1-2].

\section{METODOLOGÍA}

En el análisis estructural y morfotectónico de la Falla Río Seco se tuvo en cuenta la metodología de diferentes autores de nivel internacional que han propuesto métodos para la realización de este tipo de análisis, se emplearon equipos y materiales idóneos para la finalidad de ese trabajo (GPS, brújula, martillo geológico, mapas y herramientas para la excavación de trincheras) $[14,2,15]$. 
Fuente: Colmenares, F., et al., 2007.

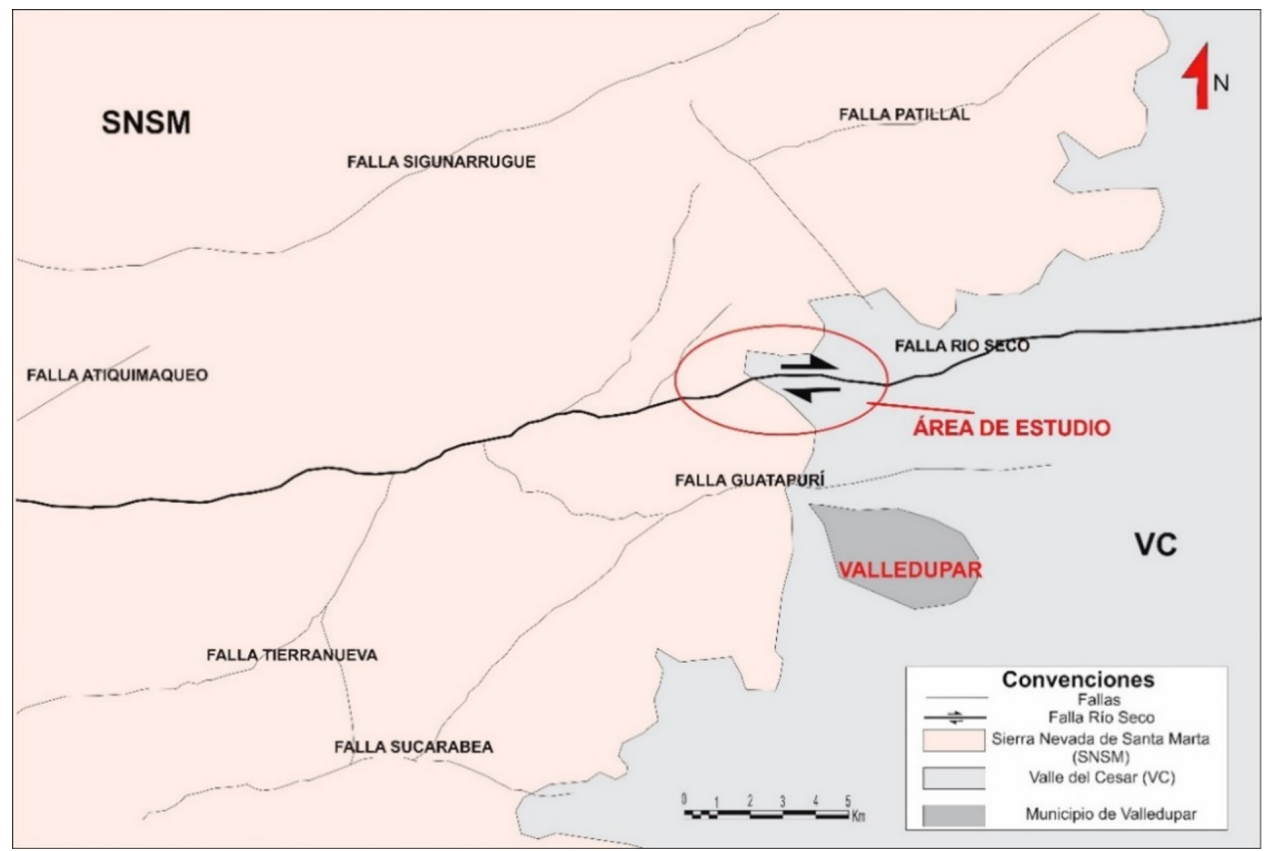

Figura 3. Principales rasgos estructurales al norte de Valledupar, pertenecientes al sistema de Fallas NE-SW. En la figura se observa el trazo de la Falla Río Seco y el área de estudio.

Tabla 1. Eventos sísmicos asociados a la Falla Río Seco, en esta se aprecian las magnitudes y profundidades de los sismos en un periodo de tiempo desde el año 2010 al 2017.

\begin{tabular}{|c|c|c|c|c|}
\hline Longitud & Latitud & Magnitud & Profundidad $(\mathbf{K m})$ & Fecha \\
\hline$-73,2240$ & 10,5980 & 2,5 & 0,00 & $16 / 07 / 2010$ \\
\hline$-73,3050$ & 10,6260 & 2,3 & 12,00 & $08 / 01 / 2011$ \\
\hline$-73,3370$ & 10,6490 & 2,4 & 0,00 & $13 / 12 / 2012$ \\
\hline$-73,3520$ & 10,6510 & 2,8 & 100,50 & $20 / 05 / 2013$ \\
\hline$-73,3050$ & 10,5940 & 3,9 & 89,90 & $25 / 08 / 2013$ \\
\hline$-73,2600$ & 10,5970 & 1,3 & 89,30 & $14 / 01 / 2014$ \\
\hline$-73,3130$ & 10,6310 & 1,9 & 83,10 & $04 / 02 / 2014$ \\
\hline$-73,2210$ & 10,6340 & 2,3 & 94,00 & $15 / 06 / 2015$ \\
\hline$-73,2060$ & 10,6560 & 2,2 & 75,20 & $23 / 08 / 2015$ \\
\hline$-73,2410$ & 10,6530 & 3,9 & 88,00 & $12 / 12 / 2015$ \\
\hline$-73,2590$ & 10,6370 & 1,5 & 91,70 & $30 / 05 / 2016$ \\
\hline$-73,3750$ & 10,6040 & 1,6 & 78,40 & $29 / 09 / 2017$ \\
\hline
\end{tabular}

Fuente: (SGC, 2018).

La metodología comprendió dos etapas fundamentales, iniciando por un análisis de los rasgos geomorfológicos y estructurales del área a través de imágenes satelitales Sentinel 2A en programas computarizados de Sistema de Información Geográfica
(ArcGis) facilitando la interpretación morfológica el área, seguido por una etapa de campo que comprendió varias fases, la primera un reconocimiento de rasgos geomorfológicos e identificación de indicios de tectónica reciente en el área, en la segunda fase se 


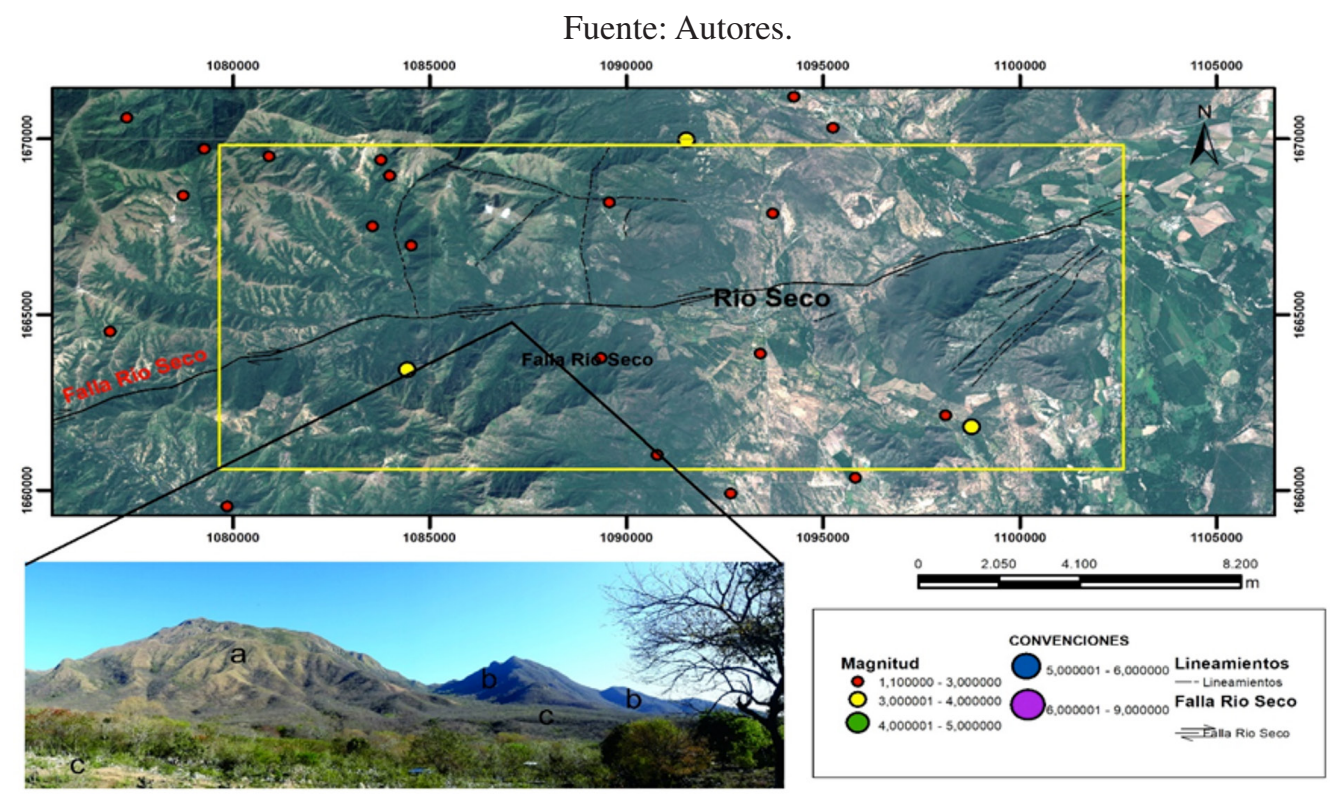

Figura 4. Actividad sísmica en el sector Río seco - Murillo entre los años 2010-2017, en donde se observa una distribución de sismos con magnitudes de 1 a 3 en la escala de Richter en los alrededores del trazo de la falla.

cartografió el trazo de la falla en el tramo de las poblaciones de Rio Seco - Murillo para observar deformaciones y fallamientos asociados. En la tercera fase se aplicaron las técnicas paleosísmicas de levantamiento de trincheras mediante la metodología descritas a continuación [15]:

1) Mediante el mapa de unidades geomorfológica del área se estableció el sitio más favorable para la construcción de la trinchera.

2) Efectuadas las excavaciones, se procedió al lavado y raspado de las paredes de la trinchera.

3) Se fotografiaron cada una de las paredes, se levantó, describió e interpretó la secuencia estratigráfica, mediante el perfil de suelo.

Con la toma de 367 datos estructurales se realiza un análisis de esfuerzos derivados procesados en el software Faulking y FaultKinWin [16], que incluyen códigos algorítmicos escritos originalmente [17]. Este software permitió determinar el sentido de los esfuerzos de la Falla Río Seco.

\section{RESULTADO Y DISCUSIÓN}

Interpretación de imágenes satelitales sentinel 2A Las imágenes satelitales permiten analizar relieves en alta resolución, por tal motivo son muy utilizadas en el estudio geomorfológico y de deformación morfológica de un área determinada. En este estudio morfotectónico se analizaron imágenes satelitales Sentinel 2A, analizadas desde el programa de sistema de información geográfica (ArcGis) donde se identificaron rasgos morfotectónico dejados por la Falla Río Seco, como escarpes de falla, evidenciada en campaña de campo en dirección NE-NW coincidiendo con la dirección preferencial de la falla. Lineamientos y microfallas fueron reconocidas en las imágenes y corroboradas en el área, identificando rastros de estriamientos (Figura $5 \mathrm{~b}$ y $5 \mathrm{~d}$ ), asociadas al fallamiento principal.

\section{Unidades geomorfológicas}

Las unidades geomorfológicas en el área se obtuvieron del [6], correspondiente a: Abanico Aluvial Antiguo, Abanicos Aluviales No Diferenciados, Cerro Remanente, Cono de Deyección, Escarpe de Líneas de Falla, Glacis de Acumulación, Mesa de Abanico, Plano de Inundación, Sierra Denudada y Terraza de Fallamiento (Figura 6). Algunas de estas unidades relacionadas con el trazo de la Falla Río Seco, como son: Escarpes de Líneas de Falla y Terrazas de Fallamiento caracterizada por relieve de moderada pendiente y procesos geomorfológicos fluviales (Figura 5a). 
Fuente: Autores.

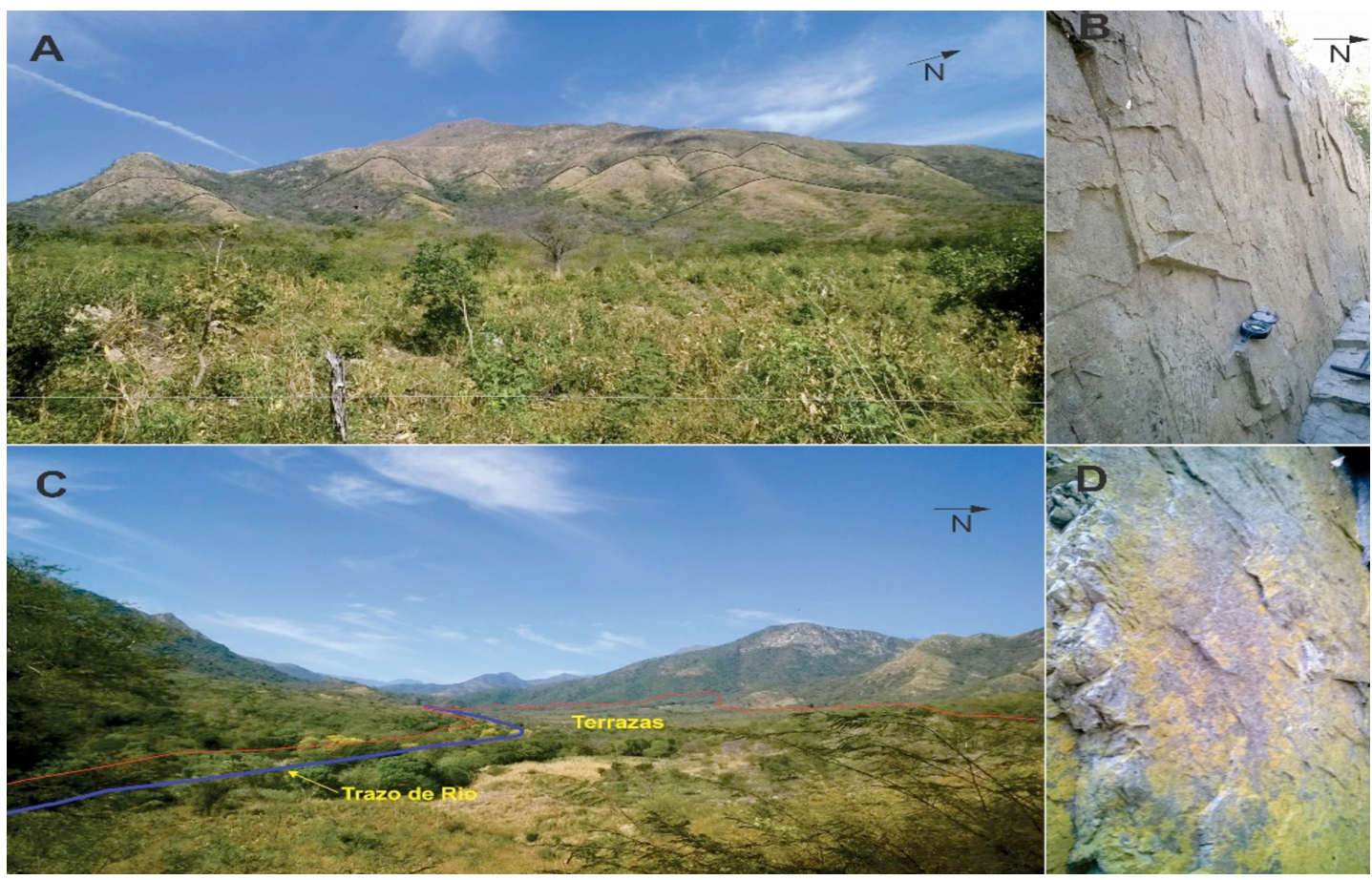

Figura 5. Se observan rasgos dejados por la Falla Río Seco y geo formas en el área. (A) Relieve de moderada pendiente. (B y D) Rasgos estructurales, estrías de falla. (C) Terrazas aluviales y trazo activo del río.

Fuente: Autores.

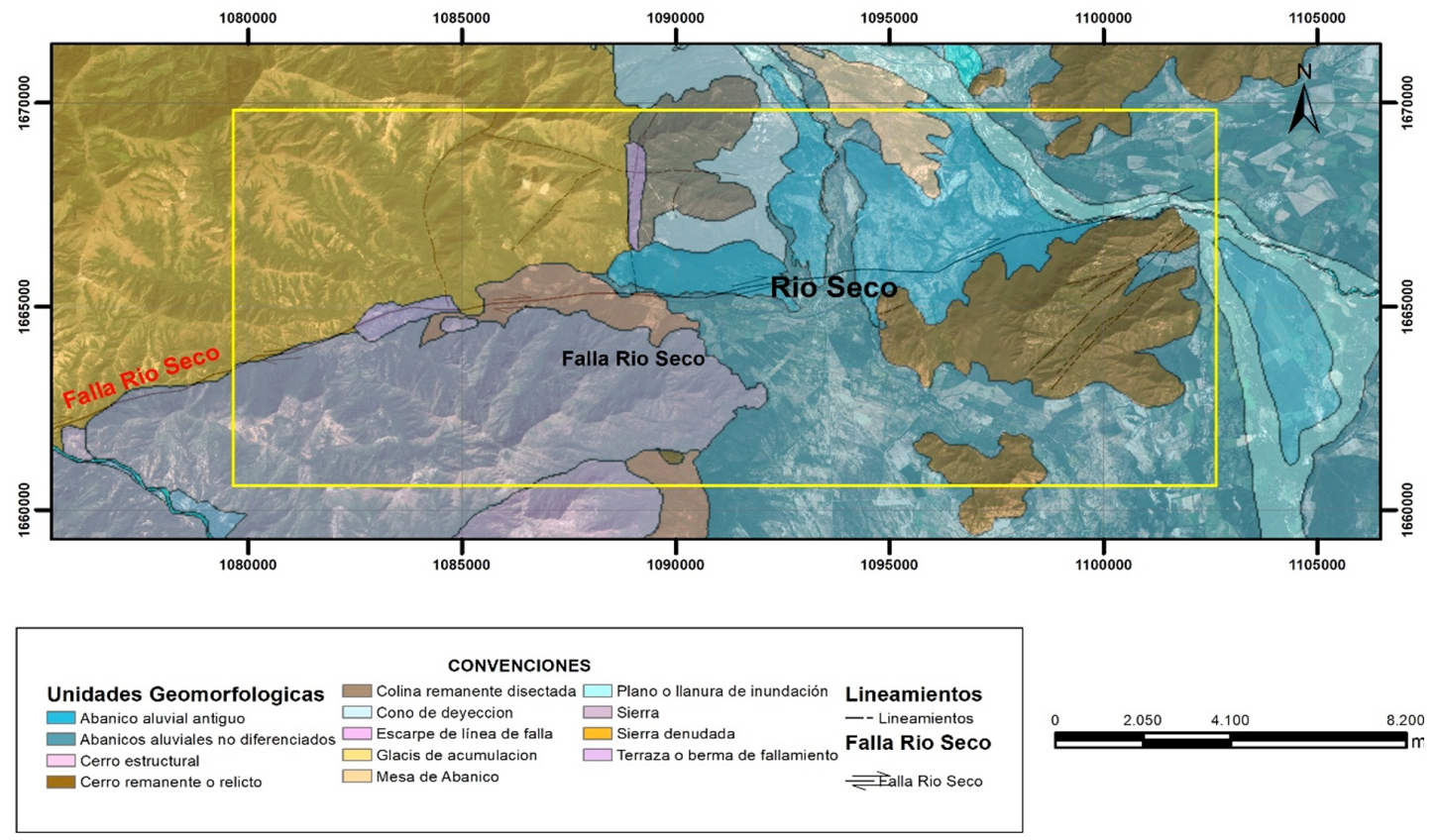

Figura 6. Rasgos estructurales y unidades geomorfológicas del área de estudio, tomado del Servicio Geológico Colombiano (2017), adaptado a partir de imágenes Sentinel 2A. 


\section{Análisis neotectónico y morfotectónico del relieve}

El análisis morfotectónico clásico, destaca algunas evidencias como escarpes de falla, basculamientos y plegamientos en depósitos Cuaternarios [18-19]. En las zonas bajas del piedemonte de la Sierra Nevada de Santa Marta se presenta una expresión morfotectónica compleja, con algunas geoformas típicas de la actividad neotectónica; como es, laguna de falla en el río La Vega del Medio coincidiendo con el trazo de la Falla Río Seco y con el cambio de dirección del río (Figura 7a), que inicialmente tenía un recorrido $\mathrm{S}-\mathrm{N}$, modificando su cauce en dirección E-W. El bloque derecho de la laguna presenta una componente de falla inversa expuesto por el desplazamiento del bloque superior, estas asociaciones se hacen relevantes sobre curvaturas que presenta la falla (Figura 7b). La actividad tectónica, evidenció escarpes de falla, lineamientos $\mathrm{y}$ fallamientos asociados a la falla principal, al igual que terrazas aluviales observadas al norte del trazo (Figura 5c).

\section{Evidencias de deformación}

Los análisis morfotectónicos brindan una valiosa información acerca de algunos rasgos en el relieve, los cuales son producidos por movimientos en el terreno, ya sea por fallas o por esfuerzos derivados. Estos análisis son importantes para las investigaciones aplicadas a la peligrosidad de origen tectónico, en áreas con sismicidad baja y una tectónica activa, por lo que se hace necesaria la definición de los esfuerzos que originan las deformaciones actuales [20]. A nivel mundial, se combinan métodos estructurales y geomorfológicos, tales como el análisis de poblaciones de fallas y pliegues para la estimación de campos de esfuerzos regionales [21], el estudio de deformaciones jóvenes en frentes de montaña [22-24].

En la cartografía realizada al trazo de la Falla Río Seco en la región de Murillo al noreste del corregimiento de Río Seco, se observaron rasgos de deformación como plegamientos en afloramientos de rocas en

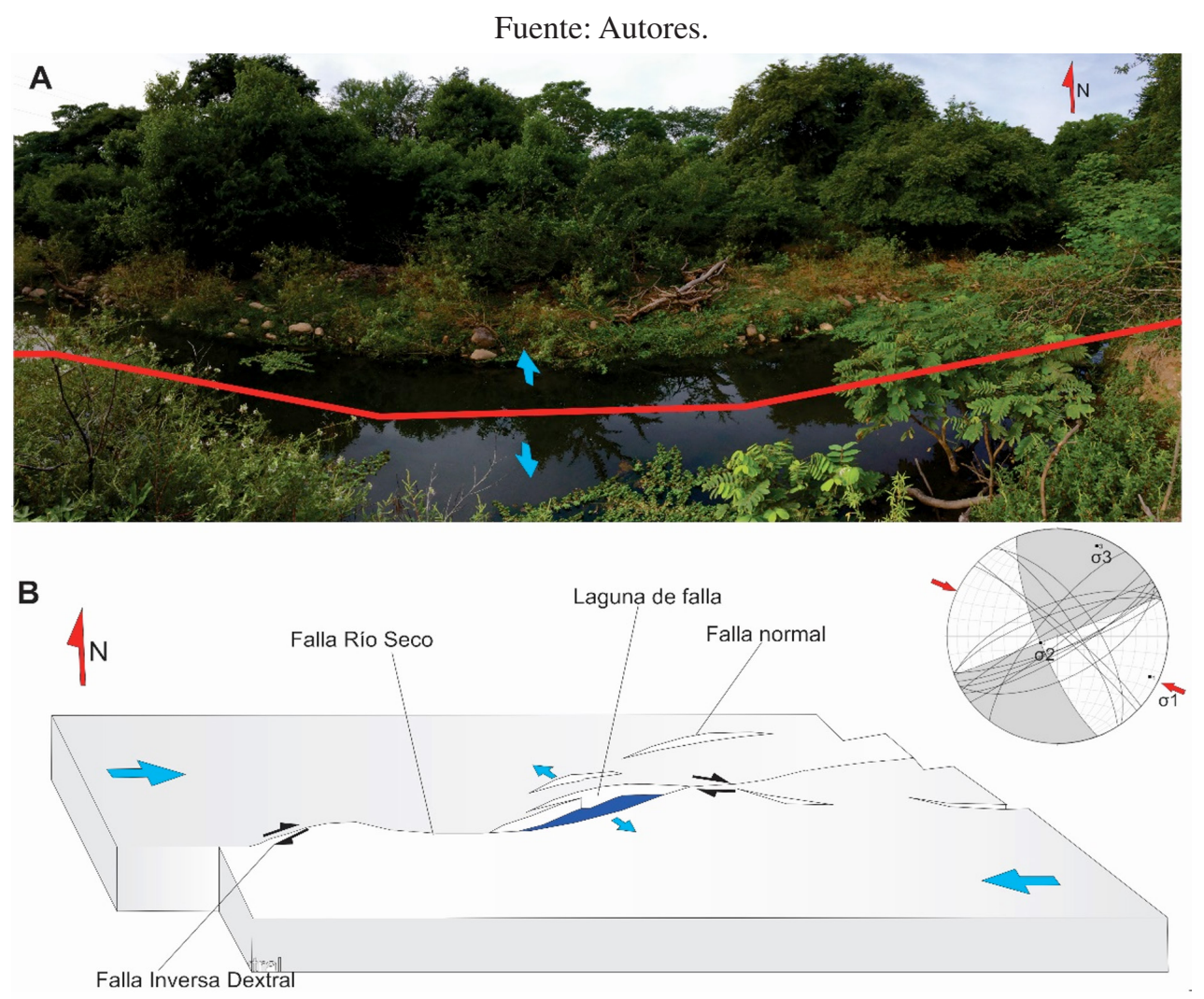

Figura 7. (A) Laguna de falla alineada con el río, producida por movimientos diferenciales del terreno. (B) Diagrama esquemático de los esfuerzos producidos sobre la laguna de falla. 
cercanías del trazo de la falla (Figura 8b), macizos altamente fracturados y rocas con altos grados de cizallamiento (Figura 8a, c). Los dos primeros rasgos son producidos por el movimiento de la falla, que produce una fracturación de macizos y deformación por esfuerzos.

\section{Deformación en las paredes de la trinchera}

Al noreste de la población de Río Seco, se seleccionó el sitio más favorable para la realización de la trinchera, debido a que no posee erosión natural, intervención antrópica, y no cuenta con un nivel freático somero cercano (ya que la acumulación de agua en la trinchera puede afectar la estabilidad de las paredes y dificultar las labores de excavación), asegurando que no haya pérdida de registros y, por consiguiente, que la historia paleosismológica esté completa.
La excavación se programó de unas dimensiones de $1,5 \mathrm{~m}$ de largo, 1 de ancho y entre 1 y $1,5 \mathrm{~m}$ de profundidad; estas dimensiones garantizaron la visualización de perfiles del suelo donde se analizaron evidencias de deformación en las paredes de la trinchera, como pequeños cambios en la dirección de los clastos, y deformaciones que no superan los ocho centímetros sobre el perfil de suelos caracterizados por granulometría predominantemente areno arcilloso con una capa de $29 \mathrm{~cm}$ de espesor, areno limoso, $11 \mathrm{~cm}$ y areno gravoso $10 \mathrm{~cm}$, de base a techo respectivamente (Figura 9a y 9b). Estas observaciones son indicadores de actividad neotectónica pasiva [15], debido a que se exponen pequeños cambios y orientaciones de deformaciones en los sedimentos del abanico aluvial, evidenciado en las paredes del apique.

Fuente: Autores.
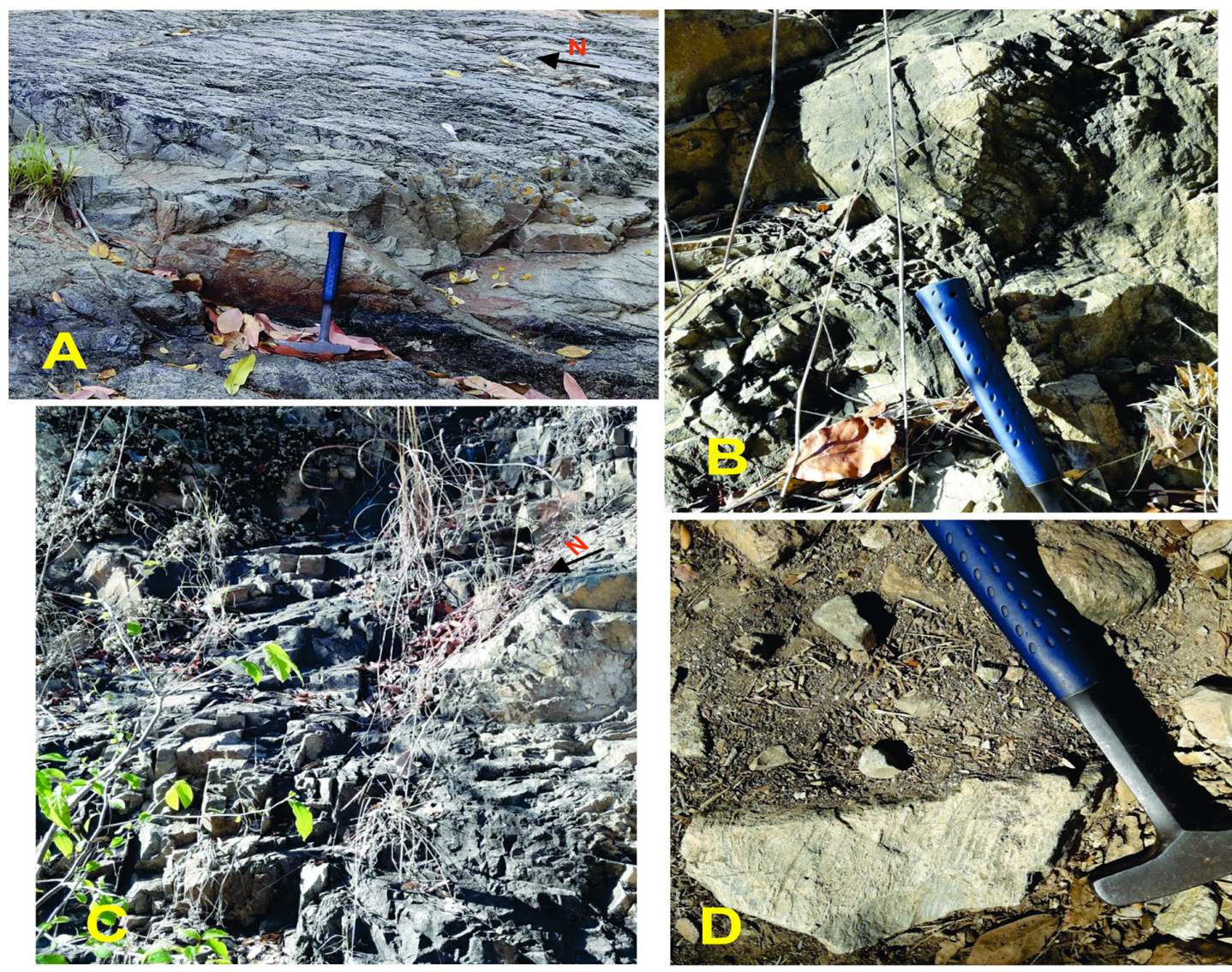

Figura 8. Rasgos de deformación provocados por el trazo de la falla. (A y C) afloramientos altamente fracturados. (B) micro plegamiento en rocas cercanas al trazo de la falla. (D) foliación. 
Fuente: Autores.

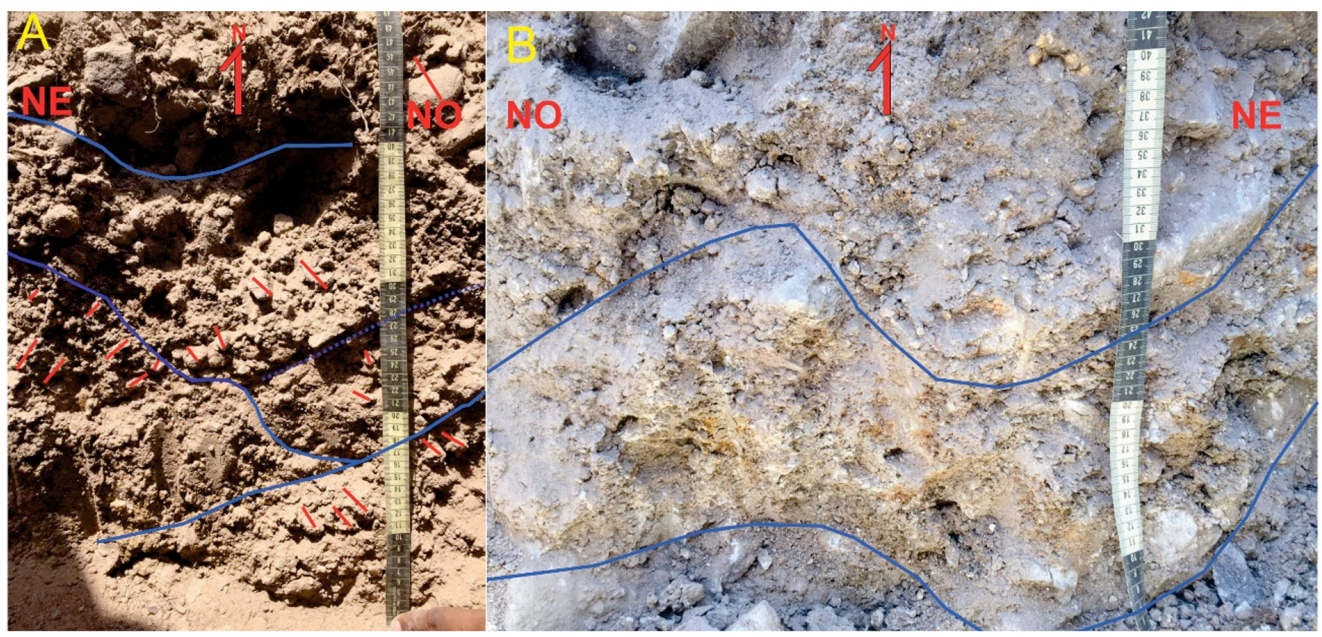

Figura 9. Rasgos de deformación evidenciada en las paredes de las trincheras ubicada en el abanico aluvial en la región de Río Seco.

\section{Análisis de esfuerzos derivados}

La Falla Río Seco en el área presenta una cinemática preferencial dextral asociadas al Sistema de Fallas NE-SW de la Sierra Nevada de Santa Marta, sin embargo, también evidencia una cinemática inversa producto de esfuerzos compresivos, asimismo, fallamientos normales perpendicular al trazo de la falla principal; dichos esfuerzos podrían ocasionar movimientos que generarían deslizamientos locales.

El área se subdivide en cuatro puntos, donde se aprecian mejor los esfuerzos asociados a la Falla Río Seco, ubicados a lo largo del trazo de la falla y lineamientos asociados como se observa en la Figura 10.

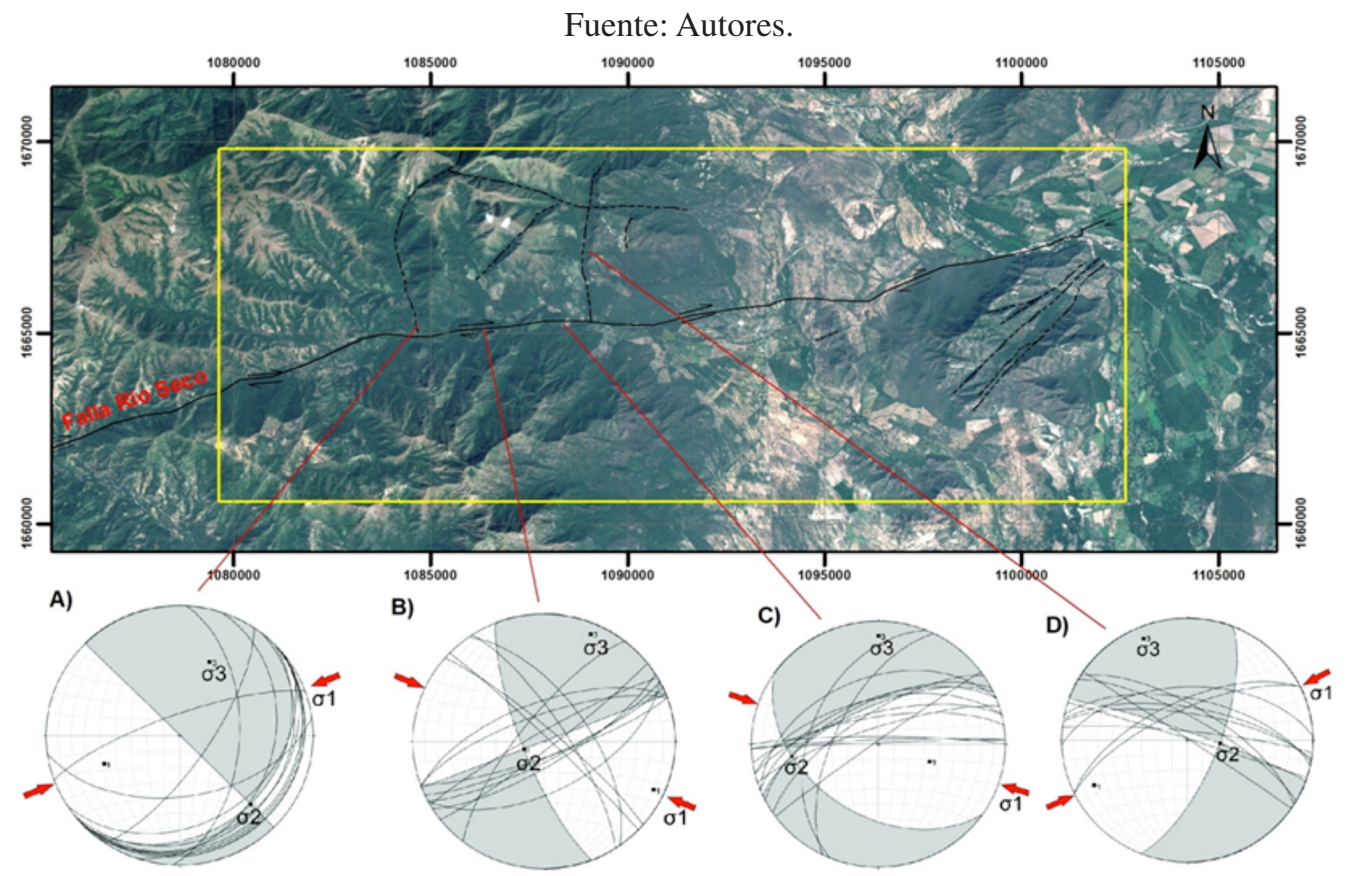

Figura 10. Análisis de esfuerzos derivados. 
Tabla 2. Esfuerzos principales compresivos.

\begin{tabular}{|c|c|c|c|}
\hline \multirow{3}{*}{ Puntos } & \multicolumn{3}{|c|}{ Medidas Lineales } \\
\cline { 2 - 4 } & $\sigma$ & Trend & Plunge \\
\hline \multirow{3}{*}{$\mathrm{A}$} & $\sigma 1$ & $245,9^{\circ}$ & $42,15^{\circ}$ \\
\cline { 2 - 4 } & $\sigma 2$ & $135,4^{\circ}$ & $21,2^{\circ}$ \\
\cline { 2 - 4 } & $\sigma 3$ & $26,2^{\circ}$ & $40,4^{\circ}$ \\
\hline \multirow{3}{*}{$\mathrm{B}$} & $\sigma 1$ & $113,6^{\circ}$ & 5,5 \\
\cline { 2 - 4 } & $\sigma 2$ & $290,3^{\circ}$ & $84,5^{\circ}$ \\
\cline { 2 - 4 } & $\sigma 3$ & $23,6^{\circ}$ & $0,3^{\circ}$ \\
\hline \multirow{3}{*}{$\mathrm{C}$} & $\sigma 1$ & $112^{\circ}$ & $57,8^{\circ}$ \\
\cline { 2 - 4 } & $\sigma 2$ & $257,7^{\circ}$ & $27,4^{\circ}$ \\
\cline { 2 - 4 } & $\sigma 3$ & $356^{\circ}$ & $15,5^{\circ}$ \\
\hline \multirow{3}{*}{$\mathrm{D}$} & $\sigma 1$ & $256,5^{\circ}$ & $13,5^{\circ}$ \\
\cline { 2 - 4 } & $\sigma 2$ & $5,9^{\circ}$ & $54,1^{\circ}$ \\
\cline { 2 - 4 } & $\sigma 3$ & $157,7^{\circ}$ & $32,6^{\circ}$ \\
\hline
\end{tabular}

Fuente: Autores.

El trend y el plunge son medidas lineales tomadas en alforamientos, fracturas, estrías, planos de estratificación que se proyectan a la horizontal y se refieren por su: Orientación "Trend" (ángulo horizontal $\alpha$ con respecto al norte) y su inclinación "Plunge" (ángulo vertical con respecto a la horizontal) [25]. Los esfuerzos principales que generaron el fallamiento en el área, para los puntos A, B, C y D son mostrados en la Tabla 2, y representados en la Figura 10 mediante el mapa de análisis de esfuerzos.

\section{CONCLUSIONES}

En la subregión del norte del Cesar se han registrado cerca de diecisiete (17) sismos asociados a la Falla Río Seco desde 1994 hasta septiembre de 2017, con magnitudes que varían entre 1,3 y 4,4 en la escala de Richter y profundidades entre 0 y $94 \mathrm{~km}$. Sin embargo, la evaluación de la amenaza sísmica con fines de reducción de la vulnerabilidad de las estructuras ante la eventualidad de un sismo no puede basarse exclusivamente en el análisis de la sismicidad histórica o instrumental, esto debido que algunos de los grandes terremotos son de baja recurrencia y su periodo de retorno es mayor que la tradición escrita de la región y que el registro instrumental.

Es recomendable aplicar técnicas más avanzadas, métodos geofísicos (líneas sísmicas, tomografías eléctricas entre otras técnicas) que puedan brindar una mayor información acerca del potencial sismológico de la Falla Río Seco.

Las estructuras geológicas de la región corresponden a fallas rumbo dextrales de dirección NE-SW representadas principalmente por la Falla Río Seco.

Mediante la interpretación por imágenes satelitales Sentinel 2A, se analizaron geoformas del relieve que evidenciaban el trazo de la falla y estructuras asociadas al fallamiento principal como microfallamientos y lineamientos que proporcionaban una buena expresión geomorfológica de área. Además, la identificación de unidades geomorfológicas en el área de estudio, escarpes de líneas de falla y terrazas de fallamiento validaron la información obtenida en campo.

Al noreste de la población de Río Seco se evidencia actividad neotectónica de la falla, el río La Vega del Medio expresa un cambio de dirección de N-S a E-W, identificándose una laguna de falla que confirma la actividad tectónica reciente.

Entre las poblaciones de Rio Seco - Murillo se observaron indicios claro de deformación producido por la falla, afloramientos altamente fracturados y microplegamientos en la roca corroboran el trazo de la falla en este sector.

En la trinchera realizada sobre el abanico aluvial al noroeste de la falla se encontraron pequeños cambios en la dirección de los clastos, y deformaciones que no superan los ocho centímetros sobre el perfil de suelos, lo que indica actividad neotectónica pasiva.

En el análisis de esfuerzos realizados, la falla presenta una cinemática preferencial dextral asociada al Sistema de fallas NE -SW. Sin embargo, se observaron componentes de fallamiento normal perpendicular al trazo. Por su parte el régimen de esfuerzos principales de falla arrojo B: $\sigma 1$ con un trend $113,6^{\circ}$ y un plunge de $5,5^{\circ}, \mathrm{C}: \sigma 1$ con un trend $112,1^{\circ}$ y un plunge de $57,8^{\circ}$ lo que indica el régimen de esfuerzos de tipo compresivos.

\section{REFERENCIAS}

[1] A.J. Crone, M.N. Machette and J.R. Browman. "Geologic investigations of theTennat Creek, Australia. Earthquake. Implications for paleoseismicity in stable continental regions". U.S. Geol. Sur. Bull., 2032-A, pp. 1-51. 1992. 
[2] M.N. Machette, A.J. Crone y J.R. Bowman. "Geologicinvestigations of the 1986 Marryat Creek, Australia, earthquake implicationsforpaleoseismicity in stable continental regions". USGS Bulletin, No 2032-B, pp. B1-B29. 1993.

[3] F. Colmenares, A. Mesa, J. Roncancio, E. Arciniega, P. Pedraza, A. Cardona, A. Romero, C. Silva, S. Alvarado, O. Romero y A. Vargas. "Geología de las Planchas 11, 12, 13, 14, 18, 19, 20, 21, 25, 26, 27, 33 y 34. Proyecto: 'Evolución Geohistórica de la Sierra Nevada de Santa Marta'”. Ministerio de Minas y Energía, Instituto Colombiano de Geología y Ministerio e Ingeominas, 2007.

[4] F.A. Audermard. "Geomorphic and geologicevidence of ongoniguplift and deformation in the Merida Andes, Venezuela". Quat. International, 101-102C, pp. 43-65. 2003.

[5] F.A. Audemard. "Paleoseismology in Venezuela: Objectives, methods, applications, limitations and perspectives". Tectonophysics, 408, pp. 29-61. 2005.

[6] Servicio Geológico Colombiano. "Mapa Geomorfológico Aplicado a Movimientos en Masa, Escala 1:100.000. Sistema de Información de Movimientos en Masa (SIMMA)”. Bogotá, 2018.

[7] Red Sismológica Nacional de Colombia. "Actividad sísmica del municipio de Valledupar- Cesar". 2018.

[8] C. Tschanz, C. Jimeno y J. Cruz. "Mapa geológico de la Sierra Nevada de Santa Marta, Colombia, 1:200.000". Instituto Nacional de Investigaciones Geológico - Mineras Bogotá, Colombia. 1969.

[9] Ceresis. "Catálogo de Terremotos para América del Sur”. Ed. Askew, B., Algermissen, S.T., CERESIS, Vol. 4, 269 p. Programa para la mitigación de los efectos de los terremotos en la región andina (Proyecto SISRA). 1985.

[10] F.A. Audemard y A. Singer. "La ingeniería de fallas activas en Venezuela: historia y estado del arte". Fundación Venezolana de Investigaciones Sismológicas, pp. 11-26. 1987.

[11] D.P. Schwartz and K.J. Coppersmith. "Fault behaviour and characteristic earthquakes: examples from the Wasatch and San Andreas
Fault zones". J. Geophys. Res; 89:5681-5698. 1984.

[12] A. Singer, C. Rojas y M. Lugo. "Inventario nacional de riesgos geológicos, estado preliminar. Mapa, glosario y comentarios". FUNVISIS, 126 p. 1983.

[13] E. Krinistzky. "Earchquake probability in engineering - Part 2: Earthquake recurrence and limitations of Gutenberg - Richter b valus for the engineering critical structures. Engineering geology". Vol. 36, pp. 1-52. 1993.

[14] A.M. Michetti, F.A. Audemard and M. Shmuel. "Futuretrends in paleoseismology: integratedstudy of seismic, landscapeisthe vital tool in seismichazardanalyses". Tectonophysics, 408, pp. 3-21. 2005.

[15] J.P. McCalpin. "Field techniques in paleoseismology Terrestrial environments". En: Mc Calpin, J.P. (Ed). Paleoseismology. International Geophysics Series 95, SecondEdition, ELSEVIER-BOOK AIDSabreFoundation, pp. 29-118. 2008.

[16] R.W. Allmendinger, N. Cardozo and D. Fisher. "Structural geology algorithms: Vectors and tensors in structural geology". Cambridge University Press, 302 p. 2012.

[17] R.A. Marrett and R.W. Allmendinger. "Kinematic analysis of fault-slip data". Journal of Structural Geology. Vol. 12, pp. 973-986. 1990.

[18] E.A. Keller. "Investigation of Active Tectonics: Use of Surficial Earth Processes". National Academy Press, Washington DC, pp. 136147. 1986.

[19] S. Lecce. "The alluvial fan problem". In Alluvial Fans, a fieldapproach. A. Rachocki and M. Church, (ed.) Chichester, J. Wiley. 1990.

[20] C. Olivera, T. Susagna, A. Roca and X. Goula. "Seismicity of the Valencia trough and surrounding areas". Tectonophysics. No 203, pp. 99-109. 1992.

[21] A. Etchecopar, G. Vasseur and M. Daigniéres. "An inverse problem in microtectonic for the determination of stress tensors from fault striation analysis". Journal of Structural Geology. Vol. 3 No 1, pp. 51-65. 1981.

[22] E. Zovoil, E. Konstantinidi and I.K. Koukouvelas. "Tectonic geomorphology of escarpments: the cases of Kompotades and Nea Anchialos Faults". Bulletin of the 
Geological Society of Greece. Vol. XXXVI, pp. 1716-1725. 2004.

[23] A.A. Tapia Espinosa. "Neotéctonica del sistema de fallas Soná-Azuero, región de Los Santos". Panamá. Tesis de Maestría. Universidad de Panamá. 2007.

[24] A.L. Casa, J.M. Cortés y M.M. Borgnia. "Evidencias de deformación pleistocena en el sistema de falla La Carrera ( $\left.32^{\circ} 40^{\prime}-33^{\circ} 15^{\prime} 1 \mathrm{~s}\right)$, Cordillera Frontal de Mendoza". Revista de la Asociación Geológica Argentina. Vol. 67 No 1, pp. 91-104. 2010.

[25] R. Lisle. "Geological Structures and Maps. A practical guide". Elsevier ButterworthHeinemann. Third edition. 2004. 